\title{
DESSALINIZADOR SOLAR PORTÁTIL: UM ARTEFATO TRANSDISCIPLINAR
}

\author{
PORTABLE SOLAR DESALINATOR: A ARTIFACT TRANSDISCIPLINARY
}
Alessandra Meireles do Amaral', Ana Regina Dalmaschio Carrijo2, Ana Nery Furlan Mendes 3 , Sandra Mara Santana Rocha ${ }^{4}$

\author{
Recebido em: 18 de dezembro de 2016 \\ Aprovado em: 05 de maio de 2017 \\ Sistema de Avaliação: Double Blind Review \\ RCO | a. 10 | v. 1 | p. 88-110 | jan./jun. 2018 \\ DOI: https://doi.org/10.25112/rco.v1i0.514
}

\begin{abstract}
RESUMO
O dessalinizador solar portátil é um artefato de ensino transdisciplinar que proporciona uma abordagem diferenciada de temas atuais e relevantes, podendo contribuir de forma significativa com o processo de aprendizagem escolar e o desenvolvimento do aluno como cidadão, conforme as exigências atuais do Ensino Médio. A sua produção e a utilização tem por objetivo a sensibilização dos alunos a respeito da problemática de escassez da água, propondo um método alternativo e de baixo custo que visa à purificação da água salgada, movido à energia solar. Dentro das abordagens curriculares deste artefato, podem-se levantar questões pertinentes às transformações dos estados físicos da matéria e separação de substâncias de uma solução, associadas ao ciclo da água e, ainda, destacar a importância da reutilização de materiais para reduzir a quantidade de lixo lançado no ambiente. Por se tratar de um objeto que contempla a temática da educação ambiental, o dessalinizador pode ser aplicado em todas as séries do Ensino Médio, dentro da área de Ciências Naturais, nas disciplinas de Biologia, Química e Física, englobando os aspectos que melhor se adequam aos conteúdos trabalhados.
\end{abstract}

Palavras-chave: Artefato de Ensino. Ensino de Química. Transdisciplinaridade.

\section{ABSTRACT}

The portable solar desalinator is a transdisciplinary teaching device that provides a differentiated approach to those current and relevant topics and can contribute significantly to the process of school learning and the development of the student as a citizen, as the current requirements of High School. Its production and use aims at raising awareness among students about the problem of water scarcity, proposing an alternative and cost of salt water purification method, working as pure solar-powered. Within the curricular approaches of this artifact, pertinent questions can be raised about the transformation of state of matter and separating substances in a solution associated with the water cycle, and also highlight the importance of reusing materials to reduce the amount of dump released into the environment. Because it is a guided object for the theme of environmental education, the desalinator can be applied to all High School grades, within the area of Natural Sciences in Biology disciplines, Chemistry and Physics, covering the aspects that best suit worked contents.

Keywords: Teaching Artifact. Chemistry Education. Transdisciplinary.

\footnotetext{
1 Mestre em Ensino na Educação Básica pela Universidade Federal do Espírito Santo (Vitória/Brasil). E-mail: meireles.ale@hotmail.com.

${ }^{2}$ Especialista em Ensino da Biologia pela Faculdade Vale do Cricaré (São Mateus/Brasil). Professora da Secretaria de Educação do Estado da Bahia (Itamaraju/Brasil).E-mail: anadalmachio@ hotmail.com.

${ }^{3}$ Doutora em Química pela Universidade Federal do Rio Grande do Sul (Porto Alegre/Brasil). Professora na Universidade Federal do Espírito Santo (Vitória/Brasil). E-mail: ananeryfm@gmail.com.

${ }^{4}$ Doutora em Engenharia Química pela Universidade Federal de Uberlândia (Uberlândia/Brasil). Professora na Universidade Federal do Espírito Santo (Vitória/Brasil).E-mail: sandra.m.rocha@ufes.br.
} 


\section{INTRODUÇÃO}

De acordo com os Parâmetros Curriculares Nacionais (BRASIL, 1999), o Ensino Médio, em suas atribuições, deve contemplar os problemas do cotidiano e questões sociais nas quais os educandos encontram-se inseridos, preparando-os para a vida através do desenvolvimento da autonomia e criticidade, tornando-os cidadãos preparados para atuar no meio onde vivem.

Esta preparação, que permite utilizar os conhecimentos em prol de uma melhoria das condições de vida, do desenvolvimento social, político e cultural, proporciona aos estudantes o desenvolvimento de problemas concretos, utilizando suas competências e conhecimentos (científicos e tecnológicos) para satisfazer as necessidades da sociedade, melhorando a sua participação perante a mesma e exercendo a sua cidadania (CACHAPUZ et al., 2005).

A capacidade de enfrentar situações do cotidiano, trabalhos em grupo, a redescoberta, a resolução de problemas de forma individual ou coletiva são exercícios de competências da vida em comunidade. É através dela que o aluno aprenderá a lidar com os limites e possibilidades de cada um e de cada grupo, usando procedimentos racionais como fundamento e consequência do agir (DELIZOICOV; ANGOTTI; PERNAMBUCO, 2009).

Contudo, o fracasso dos alunos é notório quando se propõe a análise de situações onde devem ser relacionados dados ou fatos diversos do cotidiano, ou quando é necessária a tomada de decisão entre diferentes e possíveis caminhos na resolução de problemas (BRASIL, 2002).

Segundo as orientações educacionais complementares aos Parâmetros Curriculares do Ensino Médio - PCNEM+ (BRASIL, 2002), um dos pontos de partida para a superação desse insucesso é a crescente conscientização da sociedade para a importância da educação escolar, aliada a uma maior aproximação da escola à vida do estudante, buscando contextualizar as informações e transcender os conteúdos curriculares de cada disciplina, visando integrar os conhecimentos, numa ótica de ensino transdisciplinar.

A transdisciplinaridade, como o prefixo 'trans' o indica, diz respeito ao que está ao mesmo tempo entre as disciplinas, através das diferentes matérias e além de toda ciência. Sua finalidade é a compreensão do mundo atual, e um dos imperativos para isso é a unidade do conhecimento (CONGRESSO DE LOCARNO, 1997, p.2).

Dessa forma, a transdisciplinaridade tende a buscar diferentes pontos de vista observando à interação dos conhecimentos, procurando ir além da individualidade conceitual das disciplinas, porém respeitando as diferenças e vislumbrando novas concepções do saber.

Santos (2007) ressalta que o ensino de ciências, na maior parte das escolas, vem sendo trabalhado de forma descontextualizada da sociedade e de forma dogmática, baseado num ensino meramente disciplinar. Os estudantes não conseguem identificar a relação entre o que estudam em ciências e o seu cotidiano e por isso, entendem que este estudo se resume a memorização de nomes complexos e fórmulas, classificações de fenômenos e resolução de problemas por meio de algoritmos. Por outro lado, o autor critica os professores afirmando que muitos consideram o princípio da contextualização como sinônimo de abordagem de situações do dia a dia, no sentido de descrever o fenômeno com uma linguagem científica, não explorando as dimensões sociais nas quais os fenômenos estão inseridos. Isso, muitas vezes, torna essa aparente contextualização como um pano de fundo para encobrir a abstração excessiva de um ensino puramente conceitual, sendo adicionados cada vez mais conteúdos ao currículo, como se o conhecimento isolado por si só fosse a condição de preparar os estudantes para a vida social. 
Visando promover um Ensino de Química mais significativo ao aluno, os PCNEM+ (BRASIL, 2002) sugerem a utilização de temas transversais para contextualização dos conteúdos químicos e estabelecimento de inter-relações deste com os vários campos da ciência. Desta forma, haverá uma aproximação dos conhecimentos estudados em sala de aula ao cotidiano do aluno, despertando o interesse dos estudantes pela Ciência e aguçando a sua curiosidade ao tornar a aula mais significativa e prazerosa. Essa ideia também é defendida nas Diretrizes Curriculares Nacionais Gerais (BRASIL, 2010) para a educação básica e nas diretrizes curriculares para o ensino médio - DECEN (BRASIL, 2011), que argumentam em favor do desenvolvimento de práticas educativas pautadas em temas com caráter de transversalidade, advindas da realidade do aluno.

Santos (2007, p. 33) destaca, ainda, que:

[...] a abordagem temática deve ser feita de forma que o aluno compreenda processos químicos envolvidos e possa discutir aplicações tecnológicas relacionadas ao tema, compreendendo os efeitos das tecnologias na sociedade, na melhoria da qualidade de vida das pessoas e as suas decorrências ambientais.

Segundo Jesus (2014), o Ensino da Química requer que o professor esteja preparado para mediar e possibilitar a formação de cidadãos, sendo que cabe tanto ao aluno quanto ao professor a incumbência de atuarem como sujeitos pensantes que agem e reagem de acordo com a realidade em que vivem, buscando de algum modo, uma alternativa para a melhor qualidade de vida e para o desempenho da escola como instituição de ensino.

Deste modo, o docente assume o papel de agente orientador e organizador da formação do conhecimento individual de cada estudante, tornando o ensino fonte de internalização e ressignificação da realidade. Sendo assim, a contribuição do professor torna-se imprescindível para a construção do conhecimento e para o desenvolvimento do processo de ensino-aprendizagem.

No ensino de química, o aprendizado deve possibilitar, além da compreensão dos processos químicos, a construção dos conhecimentos científicos relacionados às tecnologias, implicações ambientais, sociais, políticas e econômicas.

Conforme sugerem os PCNEM+, entre outras competências esperadas no ensino de química, o aluno precisa:

[...] reconhecer e compreender, de forma integrada e significativa as transformações químicas que ocorrem nos processos naturais e tecnológicos em diferentes contextos, encontrados na atmosfera, hidrosfera, litosfera e biosfera, e suas relações com os sistemas produtivo, industrial e agrícola (BRASIL, 2002, p. 87).

Para isto, os componentes curriculares precisam estar sincronizados ao cotidiano do aluno e devem ser apresentados de forma diversificada visando despertar o seu interesse e motivar a aprendizagem.

Assim, de acordo com Maldaner (1999), a construção do conhecimento dentro do ensino de química é feita por meio de manipulações orientadas e controladas de materiais, iniciando os assuntos a partir de algum acontecimento recente ou do próprio dia a dia ou ainda adquirido através deste ou de outro componente curricular, favorecendo ao aluno acumular, organizar e relacionar as informações necessárias na elaboração dos conceitos fundamentais da disciplina, os quais são trabalhados através de uma linguagem própria dos químicos, como: símbolos, fórmulas, diagramas, equações químicas e nomenclatura dos compostos.

Nesse sentido, uma proposta metodológica que pode auxiliar no processo de ensino-aprendizagem é a utilização das atividades experimentais. Estas podem assumir um caráter de construção do 
conhecimento, desde que os professores incentivem os alunos à percepção de conflitos cognitivos, os quais são motores da aprendizagem por conduzirem o aluno a buscar e confrontar informações, reconstruindo suas ideias e maneiras de explicar os problemas.

Para isto, o professor precisa realizar uma prospecção a respeito dos conhecimentos prévios de seus alunos. O levantamento desses conhecimentos permite ao professor estabelecer relações com o conteúdo sobre o qual se concentrará o processo de ensino, o que valoriza a aprendizagem e fundamenta a construção dos novos significados. Uma aprendizagem é tanto mais significativa para o aluno quanto mais relações ele desenvolve entre seus conhecimentos prévios e as novas informações (MOREIRA; MASINI, 1982).

Segundo Pereira e Gerstbergera (2013) uma das maiores dificuldades encontradas em sala de aula é fazer com que os alunos desenvolvam habilidades para relacionar os conceitos estudados com a aplicação no meio onde estão inseridos. E para a sua superação, é importante que o professor busque constantemente se atualizar, refletir sobre a sua prática e adotar metodologias de ensino diversificadas, como por exemplo, a utilização de materiais alternativos.

No intuito de auxiliar nesse processo e transcendendo a fragmentação de conteúdos em prol de um conhecimento unificado e acessível aos alunos - ensino transdisciplinar -, o presente trabalho propõe a criação de um artefato de ensino feito a partir de materiais alternativos, denominado dessalinizador solar portátil. Este instrumento de ensino poderá servir de subsídio ao professor para uma abordagem diferenciada de temas transversais, atuais e relevantes para a sociedade, e ao aluno, proporcionando uma maior compreensão dos saberes científicos por meio da visualização e participação nos procedimentos experimentais (LEAL, 2010).

Trata-se de um artefato pedagógico que auxiliará no desenvolvimento do educando, possibilitando a compreensão de processos químicos e a construção de conhecimentos científicos relacionada às aplicações tecnológicas e ambientais.

$\mathrm{O}$ artefato proposto destaca-se por possibilitar uma abordagem CTSA (Ciência Tecnologia Sociedade e Ambiente), a qual vem ganhando relevância nos últimos anos, pois promove uma renovação nos modos de conceber e desenvolver um ensino significativo e socialmente relevante.

Praia, Gil-Pérez e Vilches (2007, p. 151) afirmam que:

[...] as relações CTSA marcam o desenvolvimento científico, com destaque para as repercussões de todo tipo de conhecimentos científicos e tecnológicos (desde a contribuição da ciência e da técnica para o desenvolvimento da humanidade até aos graves problemas que hipotecam o seu futuro), permitindo a preparação para a cidadania na tomada de decisões.

A produção e a utilização deste artefato de ensino têm por objetivo principal a sensibilização dos alunos a respeito do problema de escassez da água, propondo um método alternativo de purificação da água salgada de baixo custo, movido à energia solar.

\section{METODOLOGIA}

\section{Caracterização da pesquisa}

O desenvolvimento deste artigo foi realizado a partir da confecção de um artefato de ensino de Química que visa promover a dessalinização da água salgada a partir da energia solar. A partir da análise qualitativa das potencialidades desse objeto de ensino, foi desenvolvida uma pesquisa descritiva da aplicação desse artefato, visando uma abordagem significativa, contextualizada e diferenciada dos conteúdos científicos escolares, referentes a temas transversais (como purificação da água, educação 
ambiental, aproveitamento da energia solar, reutilização de materiais não biodegradáveis, entre outros) voltados para as turmas de $1^{\circ}, 2^{\circ}$ e $3^{\circ}$ anos do Ensino Médio.

\section{Materiais e construção do artefato}

O dessalinizador solar portátil foi construído a partir de materiais alternativos. É um objeto de formato piramidal fabricado com canos e conexões (8 joelhos e 4 tês de $\left.90^{\circ}\right)$ de PVC reaproveitados, base de placa de fibra de vidro reaproveitada, cujas laterais são revestidas por um sistema de canaletas feitas com pedaços de rodaforros de PVC descartados em construções residenciais. A seguir estão descritas as etapas realizadas para sua construção.

\section{Bandeja}

Para a construção da bandeja foi utilizado um pedaço de uma placa de fibra vidro no tamanho de $24 \mathrm{~cm}$ de largura e $48 \mathrm{~cm}$ de comprimento, a qual foi adquirida em depósito de materiais para reciclagem. Este tipo de material pode ser encontrado para comprar em vidraçarias ou lojas de material para construção.

- Colaram-se nos quatro lados dessa placa, quatro pedaços de rodaforro de PVC, com as mesmas medidas da placa. Assim, formou-se um sistema de canaletas para a captação da água purificada.

- Em um dos lados da canaleta foi feito um orifício. Neste, foi acoplado um pedaço de mangueira de silicone de $10 \mathrm{~mm}$, com comprimento de $3 \mathrm{~cm}$, para a saída da água após o processo de condensação, como mostrado na figura 1.

- Foram feitos dois furos com distância entre si de $32 \mathrm{~cm}$, próximo dos cantos da bandeja, conforme a Figura 1 e 2.

Figura 1 - Esquema da bandeja

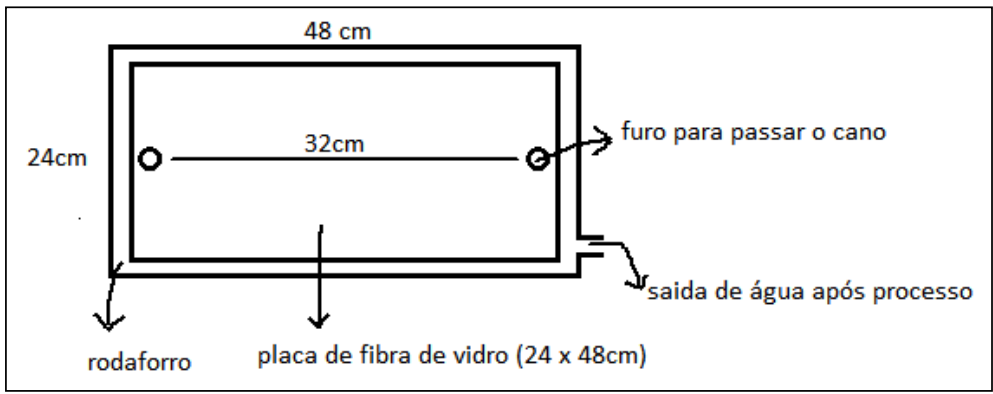

Fonte: Os autores

Figura 2 - Bandeja

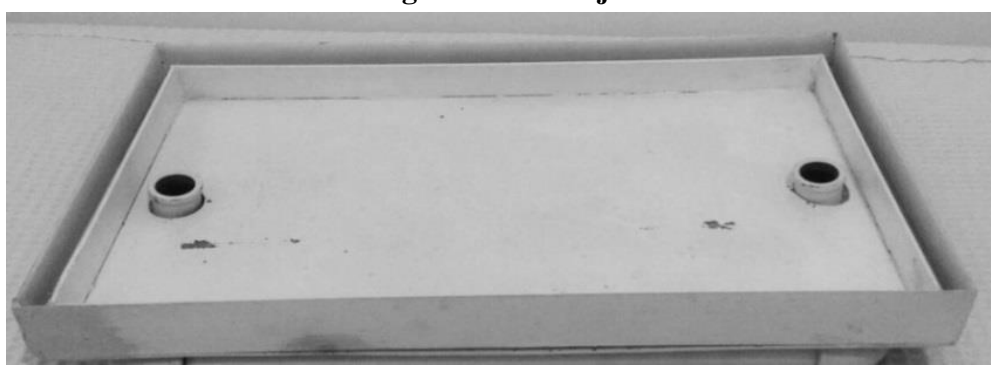

Fonte: Os autores

\section{Suporte embaixo da bandeja}

Este suporte localiza-se embaixo da bandeja e se encaixa nos furos feitos na mesma. Os materiais para sua construção foram:

- 2 pedaços de cano de $20 \mathrm{~mm}$ no comprimento de $32 \mathrm{~cm}$, 
- 4 pedaços de cano de $20 \mathrm{~mm}$ no comprimento de $8 \mathrm{~cm}$,

- 4 joelhos de $20 \mathrm{~mm}$,

- 2 tês de $20 \mathrm{~mm}$.

O suporte foi montado unindo os canos utilizando os joelhos e tês, como mostram as Figuras 3 e 4.

Figura 3 - Esquema do suporte embaixo da bandeja

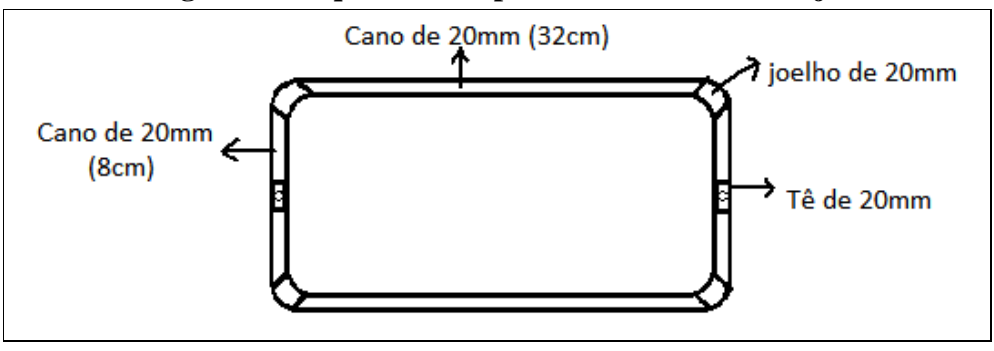

Fonte: Os autores

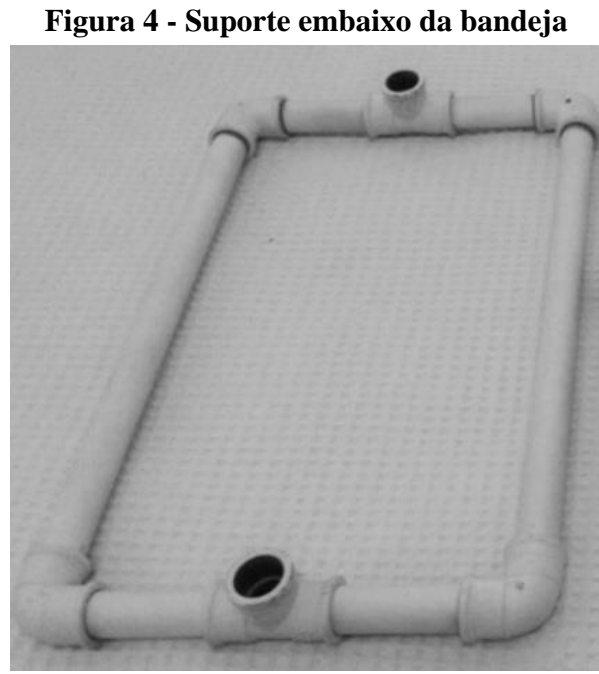

Fonte: Os autores

\section{Suporte para o filme plástico}

Este suporte foi encaixado nos tês do suporte anterior e serviu para a colocação do plástico filme. Os materiais utilizados foram:

- 1 pedaço de cano de $20 \mathrm{~mm}$ no comprimento de $32 \mathrm{~cm}$,

- 1 pedaço de cano de $20 \mathrm{~mm}$ no comprimento de $29 \mathrm{~cm}$,

- 1 pedaço de cano de $20 \mathrm{~mm}$ no comprimento de $18,5 \mathrm{~cm}$,

- 1 pedaço de cano de $20 \mathrm{~mm}$ no comprimento de 7,5 cm,

- 1 tê de $20 \mathrm{~mm}$,

- 2 joelhos de $20 \mathrm{~mm}$

O cano de 18,5 cm foi unido ao cano de 7,5 cm com a utilização do tê. Em seguida, encaixou-se o cano de $29 \mathrm{~cm}$ no cano unido pelo tê, que por sua vez, foi encaixado no cano de $32 \mathrm{~cm}$ utilizando os joelhos, de acordo com as Figuras 5 e 6. 
Figura 5 - Esquema do suporte para o filme plástico

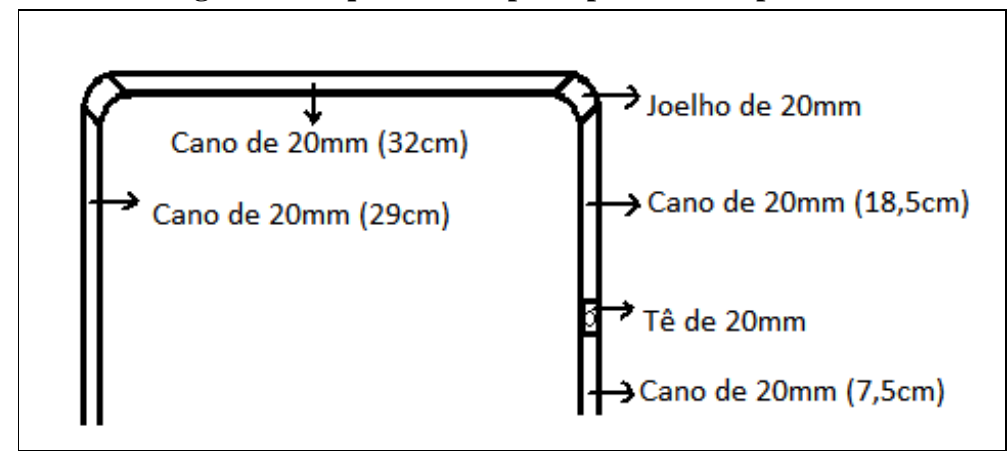

Fonte: Os autores

Figura 6 - suporte para o filme plástico

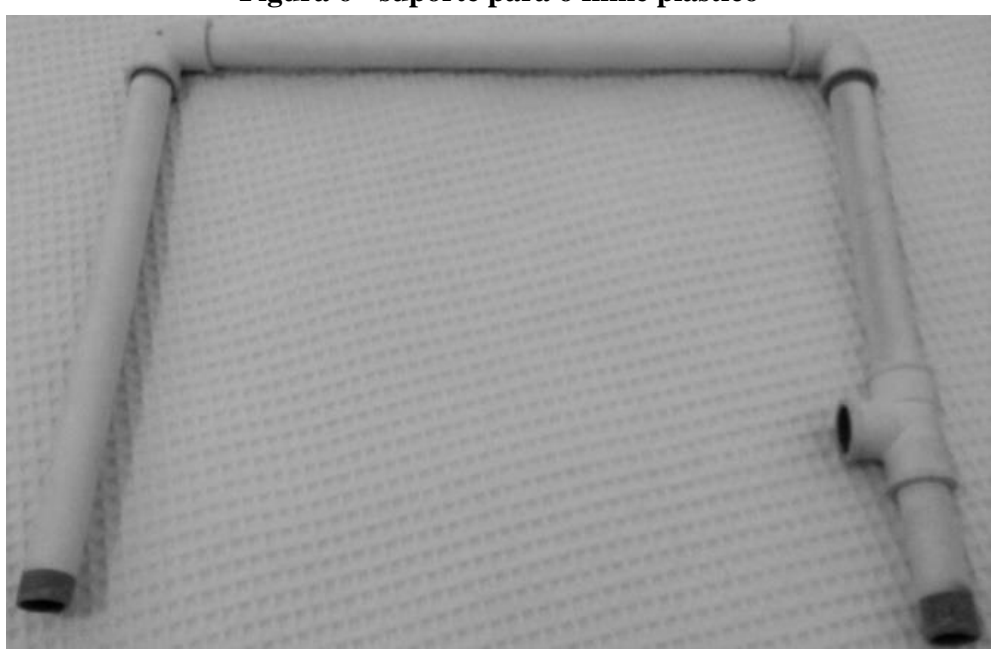

Fonte: Os autores

\section{Suporte para abastecimento de água salgada}

Para este suporte foi utilizado:

- 1 pedaço de cano de $20 \mathrm{~mm}$ no comprimento de $8,5 \mathrm{~cm}$,

- 1 pedaço de cano de $20 \mathrm{~mm}$ no comprimento de $7,5 \mathrm{~cm}$,

- 1 tê de $20 \mathrm{~mm}$ com 1 pedaço de cano no comprimento de $2 \mathrm{~cm}$ vedado com massa epóxi (para que o vapor de água não escapasse),

- 2 joelhos de $20 \mathrm{~mm}$ (um para entrada e outro para saída de água salgada).

Foram unidos os canos de 8,5 cm e de 7,5 cm utilizando o tê. Em seguida, foi colocado em cada uma das extremidades um joelho. As Figuras 7 e 8 ilustram esta parte.

Figura 7 - Esquema do suporte para abastecimento de água salgada

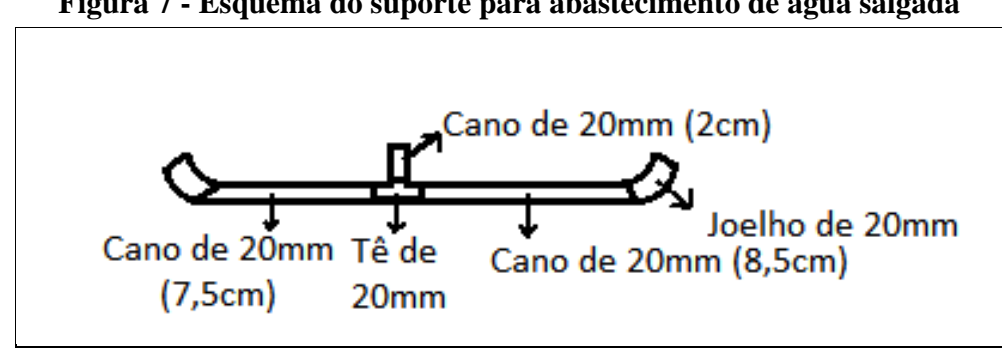

Fonte: Os autores 
Figura 8 - suporte para abastecimento de água salgada

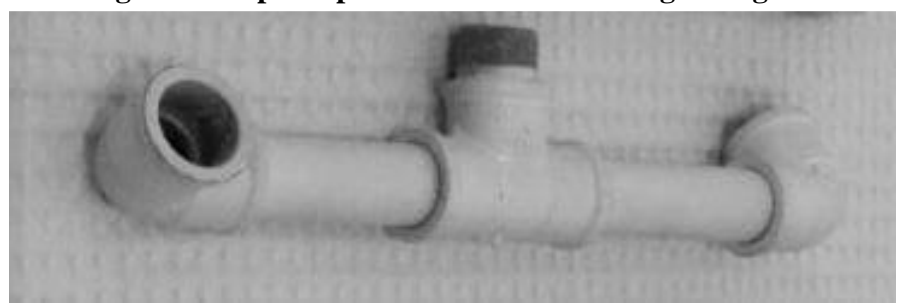

Fonte: Os autores

Com todas as partes prontas, foi encaixado o suporte de fundo embaixo da bandeja, através dos furos. Em seguida, encaixou-se o suporte para o filme plástico no suporte de fundo utilizando os tês. Por fim, foi encaixado o suporte de abastecimento no suporte de filme plástico através do tê e colocou-se o prato no centro da bandeja. A Figura 9 mostra o dessalinizador montado.

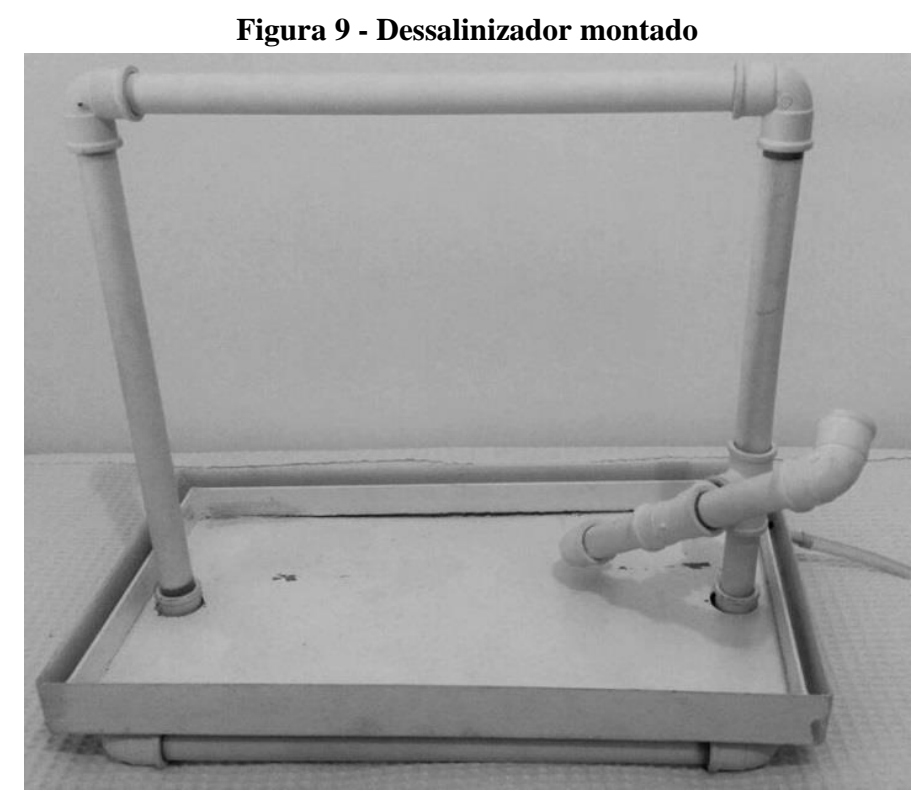

Fonte: Os autores

Após toda a montagem, o artefato foi envolvido com filme plástico de pvc de modo que não ficou nenhuma abertura, a não ser por onde ocorreu a entrada de água salgada, conforme a Figura 10.

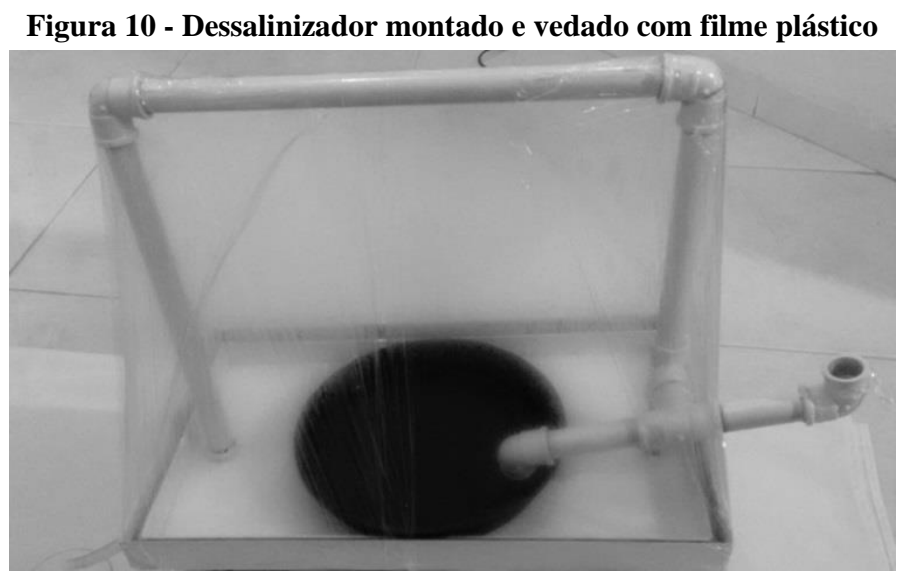

Fonte: Os autores 


\section{Reservatório de água para dessalinização}

- Foi utilizado um prato preto de plástico redondo (21 cm de diâmetro). Este prato é o mesmo utilizado para vaso de planta, conforme pôde ser observado na Figura 10.

\section{Funcionamento do dessalinizador}

Para dar início à utilização do dessalinizador é necessário envolvê-lo com um filme plástico de PVC. Em seu interior se encontra uma bandeja plástica escura (para melhor absorção do calor) que servirá de reservatório para água salgada ou salobra. Este reservatório pode ser constantemente abastecido através de um cano acoplado transversalmente aos canos de suporte*5 do filme plástico (cuja função é conectar o interior do artefato com o exterior) com o auxílio de um funil.

Após o abastecimento com água salgada ou salobra, o funil deve ser retirado e o cano precisa ser vedado com o próprio filme plástico, para evitar o escape dos vapores de água. Desta maneira, o artefato estará pronto para ser exposto a um ambiente ensolarado, onde se iniciará o processo de purificação da água salgada ou salobra, por meio da absorção de energia solar, que promoverá a transformação física denominada evaporação.

O vapor de água ascendente perde energia e condensa-se ao atingir o filme plástico de temperatura inferior e começa a escorrer até cair na canaleta de captação. A água recém-condensada escoará por meio de um orifício no canto inferior, que por sua vez, encontra-se acoplado a uma mangueira de silicone que irá destinar essa água a um recipiente coletor, estando pronta para utilização doméstica.

\section{DISCUSSÃO}

Por se tratar de um objeto transdisciplinar que trabalha a temática educação ambiental, o dessalinizador pode ser aplicado em todas as séries do Ensino Médio, dentro da área de Ciências Naturais, nas disciplinas de Biologia, Química e Física, englobando os aspectos que melhor se adequam aos conteúdos trabalhados.

Sobre as possíveis abordagens curriculares deste artefato, podem-se levantar questões pertinentes às condições atuais dos recursos hídricos no país e no mundo. Segundo Cruz (2012, p. 1), "a escassez de água tem aumentado drasticamente nas últimas décadas a nível mundial, sendo, no entanto mais evidente nas regiões áridas e semiáridas, que coincidem muitas vezes com países em vias de desenvolvimento".

Nessa perspectiva, o assunto pode ser introduzido previamente através de situações-problemas relacionando a escassez da água potável com a abundante disponibilidade de água salgada em nosso planeta. Como a escassez da água tende a se agravar cada vez mais no futuro, devido ao crescimento populacional e ao desequilíbrio do ciclo hidrológico do planeta, as técnicas alternativas de purificação de água (salgada e salobra) tem recebido um grande destaque, mostrando-se como uma possível solução para o problema em questão. Para Cruz (2012), os fatores que comprometem e agravam o equilíbrio dos recursos hídricos devem-se a uma série de eventos, tais como: "a mudança do estilo de vida; o uso ineficiente da água; a contaminação da água potável disponível, em consequência da intervenção humana sobre o ambiente e o ecossistema da água; a seca mundial e a desertificação" (Cruz, 2012, p. 2$3)$.

\footnotetext{
${ }^{5}$ Ressalta-se que a escolha pela utilização dos canos de PVC foi visando reaproveitar sobras de construções, mas que a substituição de alguns desses canos, como no caso do suporte para o filme, pode ser substituído por outros materiais alternativos, desde que não afetem o encaixe na estrutura localizado abaixo da bandeja e o encaixe dos canos transversais de abastecimento do reservatório de água.
} 
Ao contextualizar a utilização do dessalinizador solar e problematizar a situação da escassez da água, o professor levantará questões significativas, possibilitando que o aluno reflita sobre a relevância do assunto, oportunizando a construção e a apropriação do conhecimento. Conforme Delizoicov, Angotti e Pernambuco (2009, p. 201), “[...] o ponto culminante dessa problematização é fazer que o aluno sinta a necessidade da aquisição de outros conhecimentos que ainda não detém, ou seja, procurase configurar a situação em discussão como um problema que precisa ser enfrentado".

O professor poderá explorar a temática por meio de pesquisas, estimulando os alunos a reflexões e discussões, fomentando dúvidas, questionamentos e estimulando a participação de sua turma para, enfim, apresentar o artefato.

A montagem do artefato poderá ser feita juntamente com os alunos, demonstrando os materiais alternativos utilizados e ressaltando a ideia dos 3 Rs da sustentabilidade (reutilizar, reciclar e reduzir). Nessa abordagem, o professor poderá estimular a criticidade dos alunos com relação à corrida desenfreada por bens de consumo, associado à escassez dos recursos não renováveis e a contaminação do ambiente. Através do incentivo do professor, a adoção de medidas que reduzam a produção de lixo e a criação de bons hábitos de preservação do meio ambiente poderão ser desenvolvidos e disseminados pela comunidade escolar.

Para um melhor desempenho do artefato, o professor deverá aplicá-lo em um dia ensolarado. Depois de instalado, ele adicionará a água (salgada ou salobra) e o colocará em um ambiente com alta incidência de luz solar. Dentro de, aproximadamente, 15 minutos, a água será aquecida e o processo de evaporação começará a ocorrer.

Durante esse processo de aquecimento da água, a abordagem sobre a questão energética também poderá ser explorada. Nesse tópico, o professor poderá fazer um levantamento das energias alternativas e renováveis aliadas ao desenvolvimento sustentável, fazendo um paralelo com outros tipos de energias, quanto aos benefícios e prejuízos sociais, econômicos e ambientais.

Em relação à energia solar, Souza Filho (2008) afirma que essa é uma energia pura, sem vestígios de radioatividade e sem nenhum tipo de poluente. Logo, o uso da mesma seria uma alternativa energética ideal e aliada da preservação do meio ambiente. Muller e Brito (2013) também reconhecem as vantagens da energia solar, alegando que o sol é uma fonte de energia renovável, sendo esta a mais abundante no planeta, e que o Brasil é privilegiado tratando-se deste tipo de energia, pois a irradiação é extremamente alta. Isto torna o Brasil um país com grande potencial para o uso de energia solar.

Ainda sobre a temática energética, aliada a ideia de processos de purificação de água, Cruz (2012) defende que o desenvolvimento de um processo sustentável de dessalinização deve preconizar a minimização do consumo de energia e optar por formas renováveis para possibilitar o acesso de países menos desenvolvidos à água tratada. Para ela "diferentes opções utilizando energias alternativas podem ser sugeridas; no entanto, os sistemas baseados na energia solar estão entre as opções mais realísticas" (CRUZ, 2012, p. 46).

Ao iniciar o processo de condensação da água no dessalinizador solar, o professor de química, física ou biologia poderá trabalhar os processos de transformação de estado físico da matéria e separação de substâncias de uma solução, fazendo uma associação do fenômeno observado ao ciclo natural da água, conforme as recomendações dos PCNEM+. Nelas, a orientação é que o professor aborde, entre outros aspectos, “[...] as transformações químicas que ocorrem nos processos naturais e tecnológicos em diferentes contextos, encontrados na atmosfera, hidrosfera, litosfera e biosfera, e suas relações com os sistemas produtivo, industrial e agrícola" (BRASIL, 2002, p. 87). 
Dentro dos conteúdos disciplinares, existem ainda inúmeras possibilidades de exploração do artefato. Em química, além da abordagem das transformações físicas, pode-se trabalhar, por exemplo, propriedades gerais e específicas da água, solubilidade dos sais, métodos de separação de misturas, geometria das moléculas envolvidas, soluções, as reações de hidrólise, dentre outros. Na biologia, além do ciclo da água, o professor pode abordar, por exemplo, a temática do efeito estufa (em analogia ao efeito criado pelo envolvimento do artefato com filme plástico), das cadeias e teias alimentares que dependem do ciclo da água, das reações biológicas que envolvem essa substância, etc. Em física, podese trabalhar com a ideia de fontes e trocas de calor, calor específico da água, densidade da água, condução e transformação de energia, os tipos de radiações envolvidas, dentre diversas outras abordagens que se pode fazer, por se tratar de um tema que perpassa por vários conteúdos e disciplinas.

Durante todo o processo de aplicação do artefato de ensino, o professor deve estar atento ao seu papel de mediador entre o aluno e o conhecimento. Dessa forma, além de instigar o aluno a reflexões e discussões, ele deverá deixar claro quais são os seus objetivos com a aplicação desse objeto de ensino.

Para a construção da aprendizagem efetiva do aluno, o professor precisará buscar constantemente a contextualização, a significação e a articulação dos conteúdos. Deverá, ainda, trabalhar os conteúdos de forma unificada, com uma linguagem específica e adequada aos alunos, possibilitando que estes se apropriem dos conhecimentos através da sua própria perspectiva e visão da realidade (LEAL, 2010).

A avaliação da aprendizagem dos alunos poderá ser feita de forma qualitativa ao decorrer da aplicação do artefato, contemplando a participação nas discussões, a capacidade do aluno em realizar analogias e propor ideias para as problemáticas levantadas durante a exposição do artefato. Segundo Leal (2010), esse processo avaliativo deverá contemplar como aspecto principal a promoção da aprendizagem, utilizando os erros e imperfeições como indicadores de regulação para retomada de conceitos e relações conceituais carentes de aprimoramento. Sendo, assim,

[...] as avaliações precisam ser justas, bem planejadas e focadas em nossa tarefa educativa, comprometida com a promoção de nossos alunos. [...] É fundamental, nessa mesma direção, que exerçamos nossa autoridade com maturidade e equilíbrio, em toda nossa prática pedagógica e, em especial, na concepção e execução dos esquemas de avaliação que adotamos (LEAL, 2010, p. 102).

\section{CONSIDERAÇÕES FINAIS}

A utilização do dessalinizador solar colabora para a abordagem transdisciplinar dos conteúdos, buscando articulações múltiplas dos assuntos das diversas disciplinas, possibilitando uma visão mais ampla e significativa do conhecimento e da vida. Desta forma, por meio deste artefato, pretende-se tornar o ensino mais envolvente e motivar o aluno para o conhecimento científico, de forma a apresentar o conteúdo de maneira mais agradável e atraente através de atividades experimentais contextualizadas, além de aprimorar o desenvolvimento intelectual do aluno, estimulando a sua autonomia e criticidade.

Espera-se despertar o interesse dos alunos pela Ciência por meio de uma produção artesanal que promova situações de aprendizagem significativa, através de uma abordagem científica, tecnológica, social e ambiental, visando o desenvolvimento do cidadão consciente, ativo e conhecedor das questões éticas pertinente à Ciência.

\section{REFERÊNCIAS}

BRASIL. Ministério da Educação (MEC), Parâmetros curriculares nacionais para o ensino médio. Secretaria de Educação Média e Tecnológica (SEMTEC). Brasília: MEC; 1999. 
PCN+ ensino médio: Orientações Educacionais complementares aos Parâmetros Curriculares Nacionais. Ciências da natureza, Matemática e suas Tecnologias. Secretaria de Educação Média e Tecnológica - Brasília: MEC; SEMTEC, 2002.

. Conselho Nacional de Educação - Câmara de Educação Básica. Diretrizes curriculares nacionais gerais para a educação básica. Parecer CNE/CEB n. 7/2010. Brasília, 2010b. DOU de 9 de julho de 2010, Seção 1, p.10.

. Conselho Nacional de Educação - Câmara de Educação Básica. Diretrizes curriculares nacionais para o ensino médio. Parecer CNE/CEB n. 5/2011. Brasília, 2011. DOU de 24 de jan. 2012, Seção 1, p. 10

CACHAPUZ, A. et al. (Orgs.). A necessária renovação do ensino de ciências. São Paulo: Cortez, 2005.

CONGRESSO DE LOCARNO. 1997. Suíça. Evolução transdisciplinar da universidade.

CIRET/UNESCO. Disponível em: <http://ciret-transdisciplinarity.org/locarno/locapor4.php>. Acesso em: 19 mai. 2016.

CRUZ, C. E. M. Dessalinização da água do mar através da energia solar - caso de estudo: Salamansa - Cabo Verde. 2012. 115 f. Dissertação (Mestrado) - Faculdade de Ciências e Tecnologias, Universidade do Algarve, Faro. 2012.

DELIZOICOV, D.; ANGOTTI, J. A.; PERNAMBUCO, M. M. Ensino de ciências: fundamentos e métodos. 3 ed. São Paulo: Cortez, 2009.

JESUS, A. M. S. O Construtivismo e o ensino de química: contribuições para o processo de ensinoaprendizagem no ensino fundamental. Anais do V Encontro Nacional de Licenciatura (ENALIC), Natal, dezembro 2014. Disponível em: <http://enalic2014.com.br/anais/anexos/ 8072.pdf〉. Acesso em: 17 maio 2016.

LEAL, M. C. Didática da química: fundamentos e práticas para o ensino médio. Belo Horizonte, MG: Dimensão, 2010.

MALDANER, O. A. A pesquisa como perspectiva de formação continuada do professor de química. Química Nova, vol.22, n.2, pág. 289-292, 1999. Disponível em:

$<$ http://www.scielo.br/scielo.php?script=sci_arttext\&pid=S0100-40421999000200023>. Acesso em: 05 jun. 2016.

MOREIRA, M. A.; MASINI, E. A. F. S. Aprendizagem significativa: a teoria de David Ausubel. São Paulo: Moraes, 1982.

MULLER, R. L.; BRITO, A. M. A. Aquecedor solar com resíduos sólidos recicláveis. Revista Conhecimento Online. a. 5, v. 2, 2013. Disponível em:

<http://periodicos.feevale.br/seer/index.php/revistaconhecimentoonline/article/view/218>. Acesso em: 15 de setembro de 2016.

PEREIRA, D.; GERSTBERGER, J. A. O ensino da química experimental com materiais alternativos. 2013. 55 f. Trabalho de Conclusão de Curso (Graduação) - Campus Pato Branco, Universidade Tecnológica Federal do Paraná, Paraná, 2013.

PRAIA, J.; GIL-PÉREZ, D.; VILCHES, A. O papel da natureza da ciência na educação para a cidadania. Ciência \& Educação. Bauru, v.13, n.2, p.141-156, 2007. Disponível em: <http://www.scielo.br/pdf/ciedu/v13n2/v13n2a01.pdf〉. Acesso em: 10 jun. 2016. 
SANTOS, W. L. P. Contextualização no ensino de ciências por meio de temas CTS em uma perspectiva crítica. Ciência \& Ensino, vol. 1, número especial, novembro de 2007. Disponível em: $<$ http://prc.ifsp.edu.br/ojs/index.php/cienciaeensino/article/view/149/120>. Acesso em: 20 mai. 2016.

SOUZA FILHO, J. R. Projeto, construção e levantamento de desempenho de um concentrador solar cilindro parabólico com mecanismo automático de rastreamento solar. 2008. Dissertação (Mestrado em Tecnologia de Materiais; Projetos Mecânicos; Termociências) - Universidade Federal do Rio Grande do Norte, Natal, 2008. 